\title{
Skin reactions and medical protective equipment
}

\author{
Ionela Manole, Alexandra-Irina Butacu, Iulia Dudu, George-Sorin Tiplica \\ "Carol Davila" University of Medicine and Pharmacy, 2nd Department of Dermatology, \\ Colentina Clinical Hospital, "Bucharest, Romania
}

\begin{abstract}
In December 2019, healthcare authorities reported clusters of patients diagnosed with "pneumonia of unknown etiology" linked to a seafood market in Wuhan, Hubei Province, China, which were later identified as COVID-19, a rapidly spreading, atypical pneumonia caused by SARS-CoV-2, a novel coronavirus. Special protective measures were globally implemented, such as use of personal protective equipment (e.g. masks, gowns, gloves, goggles) and as washing exposed skin with soap or frequent use of disinfectants, causing an alarming increase of related skin conditions. Knowledge of the most frequent skin afflictions associated with personal protection against COVID-19 and treatment modalities represents a topic of current global interest. Increasing awareness of these medical issues is one of the most important roles of dermato-venereologists in this pandemic era and should be implemented for both the general population and the healthcare sector aiming to reduce the burden associated with these preventable skin conditions.
\end{abstract}

Keywords: COVID-19, SARS-CoV-2, skin reactions

\section{INTRODUCTION}

In December 2019, healthcare authorities reported clusters of patients diagnosed with "pneumonia of unknown etiology" linked to a seafood market in Wuhan, Hubei Province, China [1]. The pathogen agent was later identified as SARS-CoV-2 (previously known as 2019-nCoV), a novel coronavirus, [2], which induces rapidly spreading, atypical cases of pneumonia described as COVID-19 (Coronavirus Disease 2019). On January 30, 2020, the World Health Organization (WHO) declared that COVID-19 is a "public-health emergency of international concern" and strict protective measures were recommended [3]. As of March 11, 2020, the WHO declared COVID-19 a pandemic disease [4] and on May 30, 2020, up to 5817385 cases and 362705 associated-deaths were reported worldwide [5].

Healthcare workers have been actively exposed to COVID-19 as front liners and special protective measures were globally implemented. SARSCoV-2 infection can be prevented by use of person- al protective equipment (PPE) (such as masks, gowns, gloves, goggles), by washing exposed skin with soap and water and by frequent hand washing or disinfection after any contact with a potentially contaminated surface [6]. Therefore, intensive use of disinfectants (soaps, disinfectants solutions), alongside frequent skin washing and use of protective equipment may produce alterations of the skin barrier, with the appearance of allergic or irritating skin conditions (for example allergic contact dermatitis, irritative contact dermatitis, contact urticaria etc.) or may induce flare-ups of pre-existing skin conditions (for example acneiform eruptions, atopic dermatitis, allergic eczema, psoriasis, rosacea, herpes simplex virus recurrence etc.) $[7,8]$.

Knowledge of the most frequent skin conditions associated with personal protection against COVID-19 and treatment modalities represents a topic of current global interest. Increasing awareness of these medical issues should be implemented for both the general population and the healthcare sector aiming to reduce the burden associated with these preventable skin conditions. 


\section{AIM}

The aim of our work is to present the most common dermatological conditions associated with prolonged use of PPE and frequent skin washing or disinfection, alongside general recommendations for reducing discomfort and skin disease duration. Personalized consultations should not be avoided in severe or refractory cases.

\section{FACIAL DERMATOSES ASSOCIATED WITH PPE}

Facial dermatological diseases may be determined by the long-term use of protective masks (over 2 hours), glasses or visors and may include the following common clinical variants.

Acneiform eruptions appear as a consequence of increased local humidity and heat or occlusion of the pilo-sebaceous ducts and are manifested by the appearance of closed and open comedones, inflammatory papules, nodules or pustules.

Irritant or allergic contact dermatitis presents as the appearance of erythema, pruritus, stinging, erosions and fine scales (see Figure 1).

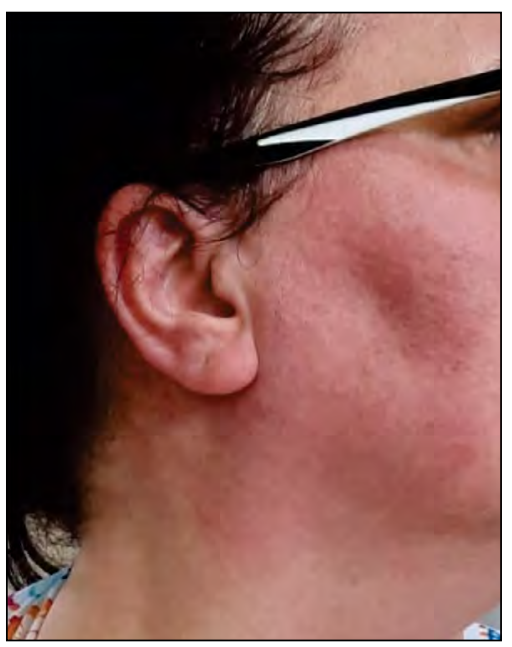

FIGURE 1. Facial allergic contact dermatitis in healthcare personnel

Aggravation of pre-existing conditions (for example rosacea, manifested as centro-facial erythema with papules and pustules or seborrheic dermatitis presented as an erythematous-squamous eruption in sebaceous areas such as the forehead, scalp, nose or chin).

Other manifestations include skin erosions caused by prolonged pressure or friction of protective equipment (e.g. retro-auricular erosions induced by the facial mask straps), skin exfoliation or post-inflammatory hyperpigmentation [9].
Recommendations for the management of facial dermatoses associated with PPE include applying emollients before use and after removal of protective equipment [8].

In case of pruritus and / or facial erythema, topical corticoids of low / medium potency are recommended for short periods of time (3 to 5 days). These may include agents such as hydrocortisone acetate, hydrocortisone butyrate, methyl-prednisolone aceponate. Oral antihistamines anti-H1 of the new generation (for example loratadine, desloratadine, cetirizine) may also be associated [10].

For acneiform eruptions, the application of agents containing benzoyl peroxide, azelaic acid or topical retinoids is indicated, keeping in mind that the initiation of therapy may associate inflammatory manifestations such as erythematous macules or papules, fine scales or crusts. In this case, it is recommended to space the applications until the adverse reactions subside so that the applications may be later resumed. Severe cases require dermatological consultation and monitored specialized treatment [10].

\section{DERMATOSES OF THE SCALP ASSOCIATED WITH PPE}

On the scalp region, dermatological conditions may appear as a consequence of extensive use of head covers or overall gowns which may induce skin damage manifested as folliculitis or the appearance / worsening of seborrheic dermatitis $[7,8]$.

Recommendations for relieving pruritus and local skin signs include topical antibiotics (such as erythromycin) or specific shampoos for the treatment of seborrheic dermatitis of the scalp (for example preparations based on ketoconazole, cyclopirox, piroctone olamine, climbazole) [10].

\section{TRUNK DERMATOSES ASSOCIATED WITH PPE}

Trunk dermatoses are most associated with extensive, prolonged use of overall gowns. Skin damage may include signs of hyperhidrosis, skin xerosis, pruritus or erythematous, scaly eruptions $[7,8]$ (see Figure 2).

Recommendations include taking showers with lukewarm water, using neutral cleaning products and applying emollients immediately after showering, on damp (not completely dry) skin [10]. 


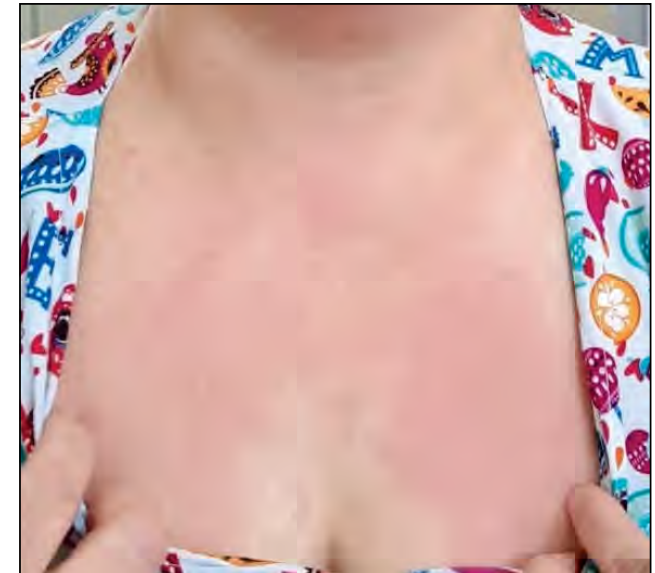

FIGURE 2. Allergic contact dermatitis of the trunk in healthcare personnel

\section{HAND DERMATOSES ASSOCIATED WITH PPE AND FREQUENT HAND WASHING}

Hand damage associated with PPE is causally link to prolonged use of medical gloves which induces the appearance of skin xerosis, fissures, hand eczema (see Figure 3), urticaria, skin maceration or erosions. Alteration of the skin barrier may predispose to infection of the skin manifested as erysipelas or cellulitis with painful, edematous, erythematous plaques of the hands and forearms $[7,8]$.

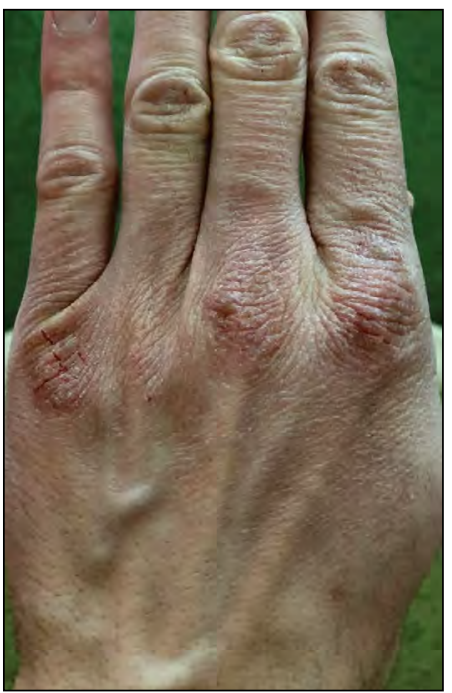

FIGURE 3. Irritant hand contact

dermatitis in healthcare personnel

Recommendations include use of vaseline-based emollients, topical corticoids of low / medium potency, antiseptic solutions (for example boric acid solution) and topical antibiotics in case of infection such as fusidic acid or gentamicin [10].

4.2. Hand afflictions associated with frequent hand washing or use of disinfectants are most commonly represented by irritant or allergic contact dermatitis (see Figure 4).

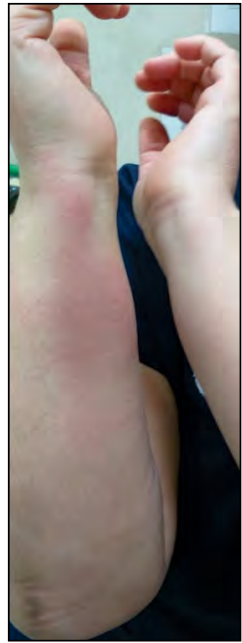

FIGURE 4. Allergic contact dermatitis of the forearms in healthcare personnel
The main irritative agents contained in the composition of disinfectants and washing products are aldehydes (formaldehyde, glutaraldehyde), glyoxal, quaternary ammonium compounds (benzalkonium chloride) [11]. Relevant allergens for healthcare professionals include acetaminophen, acetylsalicylic acid, amoxicillin, bacitracin, captopril, carbamazepine, cephalexin, cefotaxime, chloramphenicol, chlorpromazine, ciprofloxacin, dicrythromycin, cotrithromycin, cotrylamine, ibuprofen, ketoprofen, norfloxacin, piroxicam, tetracycline. Caution is advised when administering these drugs [12].

Patients may report itching, stinging or tingling in the affected areas of the skin. Clinical examination identifies papules or erythematous plaques, blisters, fissures, erosions, ulcerations, scaling or crusts $[13,14]$. Alteration of the skin barrier may predispose to infection of the skin with the appearance of pustules and purulent crusts. In this context, it is also possible to trigger a recurrence of herpes simplex virus infection with the appearance of vesicles arranged in a bouquet on an erythematous base. Eczema-type skin damage can be mild (discrete and imprecisely delimited erythema, fine scales), moderate (well-defined erythematous-vesicular papules or plaques, scales) or severe (erythematous-vesicular-papular papules or plaques with serous scales and hemorrhagic crusts. The lesions can be localized, disseminated or generalized.

Recommendations for hand hygiene include use of an anti-viral, anti-bacterial hand disinfectant with a minimum of $60 \%$ ethyl alcohol or $70 \%$ isopropanol alcohol if there are no visible signs hand impurities [15]. In case of visible impurities, the hands and the rest of the skin (including the face and scalp) can be washed with soap and water requiring at least 30 seconds of contact for providing an anti-viral effect. 
Special requirements of careful washing and rinsing may be necessary for sensitive skin on the face and folds (such as interdigital areas). Medical personnel should not wear jewelry (for example rings, earrings) during the working hours. Brushes, nail brushes, abrasive soaps or other abrasive objects should not be used to wash exposed skin.

The predictive elements associated with low compliance of proper hand hygiene are represented by medical staff working in intensive care units, staff working on public holidays and male healthcare staff [16]. These risk groups should benefit from additional counselling time on proper hand hygiene techniques.

In order to prevent the appearance of eczema, it is recommended to apply emollients [17] in a thin layer after each use of disinfectant or after washing hands with soap and water (in this case the emollient should be applied on moist skin) [18]. Emollients containing petrolatum or ceramide are recommended. Emollients which do not contain perfumes, dyes or urea are preferred [19].

In case of cutaneous inflammatory manifestations, topical corticoids of low to medium potency such be applied in a thin layer twice daily, in the morning and evening. During the day, emollients should be applied after hand washing with soap and water. For the relief of eczema-induced pruritus, the administration of new generation anti-H1 antihistamines may be beneficial.

In case of associated infection of lesions, use of antiseptic solutions (such as sanitary alcohol, hy-

\section{REFERENCES}

1. Zhu N, Zhang D, Wang W, Li X, Yang B, Song J, Zhao X, Huang B, Shi W, Lu R, Niu P. A novel coronavirus from patients with pneumonia in China, 2019. New England Journal of Medicine. 2020:727-733.

2. Wu D, Wu T, Liu Q, Yang Z. The SARS-CoV-2 outbreak: what we know. International Journal of Infectious Diseases. 2020.

3. Li X, Wang W, Zhao X, Zai J, Zhao Q, Li Y, Chaillon A. Transmission dynamics and evolutionary history of 2019-nCoV. Journal of Medical Virology. 2020;92(5):501-11.

4. World Health Organization. Coronavirus disease (COVID-19) Situation Report - 51. 11 March 2020 [Accessed on 31 May 2020]. Available from: https://www.who.int/docs/default-source/coronaviruse/ situation-reports/20200311-sitrep-51-covid-19. pdf?sfvrsn=1ba62e57 10.

5. World Health Organization. Coronavirus disease (COVID-19) Situation Report - 131. 30 May 2020 [Accessed on 31 May 2020]. Available from: https://www.who.int/docs/default-source/coronaviruse/ situation-reports/20200530-covid-19-sitrep-131. pdf?sfvrsn=d31ba4b3_2.

6. Ministerul Sănătății. Recomandări privind conduita socială responsabilă în prevenirea răspândirii coronavirus (COVID-19). [Accessed on 20 April 2020]. Available from: http://www.ms.ro/ recomandari-privind-conduita-sociala-responsabila-in-prevenirearaspandirii-coronavirus-covid-19/. drogen peroxide, boric acid solution) is indicated, followed by the application of topical antibiotics such as fusidic acid or topical combinations containing antibiotics.

Patients suffering from chronic irritative lesions of the hands accuse the intensification of symptoms (stings, itching etc.) when using disinfectants or washing with soap and water. In these cases, the reduction of the number of these procedures or the replacement with a simple rinse with water may be chosen by the patient [20]. In order to not compromise the result of disinfection or washing, the attending physician will have to prevent this behavior by encouraging patients to use emollients and to apply topical treatment.

Cases with severe or extensive skin damage require specialized dermato-venereology consultation and treatment.

\section{CONCLUSIONS}

Dermatological conditions associated with frequent washing and disinfection procedures, alongside prolonged use of PPE may induce a major negative impact on the quality of life and on the effectiveness and productivity of working activities for the healthcare workers and the general population. One of the most important roles of dermato-venereologists in this pandemic era is to raise awareness and to help implement safe and efficient prevention measures of these afflictions.

Conflict of interest: none declared Financial support: none declared

7. Foo CC, Goon AT, Leow YH. Adverse skin reactions to personal protective equipment against severe acute respiratory syndrome - a descriptive study in Singapore. Contact Dermatitis. 2006;55:291-294.

8. Elston DM. Letter from the Editor: Occupational skin disease among healthcare workers during the Coronavirus (COVID-19) epidemic. J Am Acad Dermatol. 2020.

9. Singh M, Pawar M, Bothra A, Maheshwari A, Dubey V, Tiwari A, Kelati A. Personal protective equipment induced facial dermatoses in healthcare workers managing COVID-19 cases. Journal of the European Academy of Dermatology and Venereology. 2020.

10. Yan Y, Chen H, Chen L, Cheng B, Diao P, Dong L, et al. Consensus of Chinese experts on protection of skin and mucous membrane barrier for healthcare workers fighting against coronavirus disease 2019. Dermatol Ther. 2020:e13310.

11. Lachapelle JM. Antiseptics and Disinfectants. Kanerva's Occupational Dermatology. 2020:493-506.

12. Reddy R, Maibach HI, Belsito DV. Healthcare workers. Kanerva's Occupational Dermatology. 2020:2061-2071.

13. Elston DM. Letter from the Editor: Occupational skin disease among healthcare workers during the Coronavirus (COVID-19) epidemic. Journal of the American Academy of Dermatology. 2020.

14. Yan Y, Chen H, Chen L, Cheng B, Diao P, Dong L, et al. Consensus of Chinese experts on protection of skin and mucous membrane barrier 
for healthcare workers fighting against coronavirus disease 2019. Dermatol Ther. 2020:e13310.

15. CDC Statement for Healthcare Personnel on Hand Hygiene during the Response to the International Emergence of COVID-19. [Accessed on 31 May 2020]. Available from: https://www.cdc.gov/coronavirus/2019ncov/hcp/hand-hygiene.html?CDC_AA_

refVal=https $\% 3$ A $\% 2 F \% 2 F w w w . c d c . g o v \% 2 F$ coronavirus $\% 2 F 2019$ ncov\%2Finfection-control\%2Fhcp-hand-sanitizer.html.

16. Hugonnet S, Pittet D. Hand hygiene - beliefs or science?. Clinical microbiology and infection. 2000;6(7):348-54.

17. Tiplica GS, Boralevi F, Konno P, Malinauskiene L, Kaszuba A, Laurens C, Saint-Aroman M, Delarue A. The regular use of an emollient improves symptoms of atopic dermatitis in children: a randomized controlled study. Journal of the European Academy of Dermatology and Venereology. 2018;32(7):1180-7.

18. AAD. Dry skin relief from covid-19 handwashing. [Accessed on 20 April 2020]. Available from: https://www.aad.org/public/everyday-care/ skin-care-basics/dry/coronavirus-handwashing/.

19. Duval C, Lindberg M, Boman A, Johnsson S, Edlund F, Lodén M. Differences among moisturizers in affecting skin susceptibility to hexyl nicotinate, measured as time to increase skin blood flow. Skin Research and Technology. 2003;9(1):59-63.

20. Winnefeld M, Richard MA, Drancourt M, Grob JJ. Skin tolerance and effectiveness of two hand decontamination procedures in everyday hospital use. British Journal of Dermatology. 2000;143(3):546-50. 